\title{
COVID-19 Y EL CONTRATO DE SEGUROS. IMPLICANCIAS O NO DE ESTA REALIDAD EN LOS PRINCIPIOS DEL SEGURO.
}

\author{
BREVES REFLEXIONES
}

\section{COVID-19 AND THE INSURANCE CONTRACT. IMPLICATIONS OR NOT OF THIS REALITY IN THE PRINCIPLES OF INSURANCE. BRIEF REFLECTIONS}

\author{
ENRIQUE RODRIGO PENADÉS ZANOLLI* \\ Fecha de recepción: 30 de abril 2020 \\ Fecha de aceptación 15 mayo 2019 \\ Disponible en línea: 30 de junio 2020
}

Para citar este artículo/To cite this article

Penadés Zanolli, Enrique Rodrigo. COVID-19 y el contrato de seguros. Implicancias o no de esta realidad en los principios del seguro. Breves reflexiones, 52 Rev.Ibero-Latinoam.Seguros, 68-80 (2020). https://doi.org/10.11144/Javeriana.ris52.ccsi

doi: 10.11144/Javeriana.ris52.ccsi

\footnotetext{
* Abogado uruguayo, especializado en Responsabilidad Civil y Seguros, egresado de la Universidad de la República, Postgrado en Responsabilidad Civil Profundizada (Universidad Católica del Uruguay), miembro de CILA y AIDA Uruguay (Comisión de Jóvenes), abogado en Estudio Jorge Barrera \& Asociados, Montevideo (Uruguay). Docente de "Marco legal de la actividad aseguradora" en Instituto BIOS (Uruguay). Contacto: rpenades@estudiobarrera.com.uy; er.penades@gmail.com
} 


\title{
RESUMEN
}

¿Qué implicancias puede tener la actual situación sanitaria mundial - la pandemia conocida como COVID-19 sobre los principios generales del seguro, tal como los conocemos hasta hoy? ¿Estamos frente a una situación tan extraordinaria, tan atípica que amerite plantear la posibilidad de reinterpretar los principios y las obligaciones emergentes de los contratos de seguros? Pues no considero que la coyuntura sanitaria mundial provocada por la actual epidemia revista las características de imprevisibilidad y excepcionalidad necesarias para alterar la aplicación de los principios tradicionales del seguro. No encuentro tampoco justicia en el hecho de habilitar excepciones o reinterpretaciones de las pólizas bajo el pretexto de una "excesiva onerosidad superviniente" a raíz de esta pandemia, por ejemplo, como propone la Teoría de la Imprevisión, o apoyado en argumentos que recurren a la Fuerza Mayor, al Caso Fortuito o a la Agravación del Riesgo.

Palabras Clave: Análisis, consecuencias, COVID-19, fuerza mayor, imprevisión, seguros, emergencia sanitaria, pandemia.

\begin{abstract}
What implications can the current global health situation -COVID-19- have on general insurance principles as we know them to date? Are we facing a situation so extraordinary, so atypical that it is worth considering the possibility of reinterpreting the principles and obligations emerging from insurance contracts? Well, I do not consider that the world health situation caused by the current epidemic has the characteristics of unpredictability and exceptionality necessary to alter the application of traditional insurance principles. Nor do I find justice in the fact of enabling exceptions or reinterpretations of the policies as proposed by The Theory of Unpredictability, or supported by arguments that resort to the Force Majeure, Fortuitous Case or Risk Aggravation.
\end{abstract}

Keywords: COVID-19, force majeure, insurance contract, insurance principles, pandemic.

\section{SUMARIO}

1. Advertencia. 2. Grandes miedos, pocas certezas, muchas interrogantes.

3. La incertidumbre y la imprevisión. 4. ¿Pandemia o lockdown? Referencias bibliográficas. 


\section{ADVERTENCIA}

Previo a ingresar en el análisis, entiendo necesario recordar la salvedad de que las opiniones que aquí se expresarán pueden admitir excepciones o matices puntuales en virtud de las características propias de cada cobertura, de cada región, de cada proceso de negociación previo a la emisión de una póliza, en definitiva: de la enorme casuística que rodea al mundo de los seguros.

\section{GRANDES MIEDOS, POCAS CERTEZAS, MUCHAS INTERROGANTES}

Cuando surgió la propuesta de generar reflexiones acerca de la injerencia que puede tener, en la realidad actual del seguro, la actual pandemia provocada por el virus SARS-CoV-2 (más conocido por todos como COVID-19 o "Coronavirus"), mi principal desvelo fue tratar de aportar al pensamiento crítico a partir de información confiable, datos ciertos y estudios respaldados por el empirismo y la ciencia. En otras palabras, tratar de llegar a la información objetiva y pura que se oculta detrás de la cortina del acoso científico-mediático que ha copado todos los ámbitos de la prensa y redes sociales en la actualidad y que amenaza incluso con reducir el debate público a su más mínima expresión. Pues bien, he aquí el primer y fundamental escollo que, francamente, aún no he logrado superar.

¿Qué tan imprevisible era que pudiera ocurrir algo así? ¿Qué indicadores, datos, gráficas debemos tomar en cuenta para evaluar la excepcionalidad o no de esta pandemia: ¿El índice de letalidad del virus? ¿La tasa de contagio? ¿La cantidad de muertes? ¿La velocidad de propagación? ¿La extensión geográfica? Y yendo al ámbito que nos convoca: ¿Qué tan grave es este virus como para justificar la adopción de soluciones excepcionales, comúnmente ajenas al instituto de los seguros? ¿Por qué el riesgo de sufrir perjuicios como consecuencia de una pandemia (entendida como toda enfermedad que aqueja simultáneamente a un gran número de personas, con mayor o menor alcance geográfico) debería tener, en este caso particular del COVID-19, un tratamiento distinto a cualquier otro riesgo asegurable?

Todas estas dudas, entre muchas otras, surgieron de inmediato como letreros de advertencia antes de entrar a un túnel. Y debo confesar que casi todas ellas siguen ahí, estoicas, desafiantes. Eso no significa, sin embargo, que nuestro esfuerzo intelectual sea en vano. Por el contrario, la duda es lo que nos mueve, es el alimento de la filosofía.

Si repasamos algunos datos para contextualizar este momento actual de la humanidad en perspectiva histórica (con la necesaria salvedad de que a medida que retrocedemos en el tiempo disminuye la fidelidad de los números) vemos que no es fácil comparar los distintos episodios epidémicos entre sí, por múltiples razones. El paso del tiempo, con el consiguiente avance tecnológico de la medicina y las comunicaciones, ha permitido que en la actualidad sea posible detectar y aislar los casos de este virus para estudiarlos, cuantificarlos y consolidarlos, al tiempo que ha permitido también com- 
partir esta información en forma casi instantánea en cualquier lugar del mundo. Esto nunca había sucedido antes y es verdaderamente disruptivo.

El antecedente más cercano en el tiempo nos remonta diez años atrás (2009-2010), en ocasión de la pandemia ocasionada por la llamada "gripe porcina" o "H1N1", y en este caso la información también es poco certera. Los datos oficiales hablan de una cantidad de contagiados confirmados que ronda el millón y medio de $\operatorname{casos}^{1}$ y una estimación de entre 700 y 1.400 millones de contagios reales, no diagnosticados ${ }^{2}$. Los fallecidos se estiman que fueron entre 150.000 y 575.000 , lo que nos demuestra un margen de error demasiado grande ${ }^{3}$.

Más allá de lo odioso de las comparaciones y lo poco fiable que puedan ser las cifras, lo que es indiscutible es que las diferentes pandemias o epidemias han existido siempre y han marcado significativamente el decurso de la historia de la humanidad a lo largo de los siglos. La Peste Negra (siglo XIV), la Peste Rusa (Siglo XVIII), el Cólera y la Viruela (siglo XIX), la Gripe Española, el Ébola, la Peste de Hong Kong, el SARS, el Sarampión (Siglo XX) y, ya en nuestro siglo, la reciente Gripe Porcina, todas han causado estragos y están presentes en la memoria colectiva de cada pueblo y de la humanidad toda.

Entonces, sin perjuicio del importante escollo que supone la falta de información fiable en cada caso, lo más importante a los efectos de estas reflexiones es que este episodio no es inédito. Ergo, no existe -a priori- ninguna razón para pensar que la actual pandemia COVID-19 vaya a ser la última. En todo caso, la evidencia sugiere exactamente lo contrario. Y esto influye de manera decisiva, a mi humilde modo de ver, en la categorización jurídica de un evento como "excepcional" o "imprevisible". ¿Era verdaderamente imprevisible la aparición de una pandemia como ésta? ¿Puede ser imprevisible un fenómeno que ha acontecido siempre y que se repite con cierta periodicidad a lo largo de la historia? ¿El COVID-19 es una enfermedad generalizada realmente excepcional en este contexto histórico que acabamos de repasar? ¿Tiene este virus alguna característica especial que justifique la calificación de esta pandemia como un hecho histórico sin precedentes, capaz de hacer tambalear la eficacia obligacional de los contratos, instrumento por excelencia de seguridad jurídica? Veámoslo.

En principio, tal como veníamos viendo, la gran cantidad de episodios epidémicos que ha registrado la historia humana conocida ya nos permite deducir razonablemente que el surgimiento de enfermedades nuevas, para las cuales no hemos desarrollado los debidos anticuerpos, capaces de extenderse globalmente a distintos territorios por efecto del contagio interpersonal, no parece ser algo imprevisible. De hecho, desde el punto de vista de la dinámica biológica, es esperable que las cepas de los virus muten con el paso del tiempo, incorporando aquellas características que lo ayudan a propagarse y

\footnotetext{
1 https://www.who.int/csr/don/2009_11_27a/en/.

2 Heath, Kelly; Peck, Heidi A.; Laurie, Karen L. (5 de agosto de 2011). «The Age-Specific Cumulative Incidence of Infection with Pandemic Influenza H1N1 2009 Was Similar in Various Countries Prior to Vaccination».PLOS One.

3 «First Global Estimates of 2009 H1N1 Pandemic Mortality Released by CDC_Led Collaboration | CDC». cdc.gov (en inglés). 25 de junio de 2012. Consultado el 31 de enero de 2020.
} 
eliminando aquellas que le dificultan esta tarea. Más aún en el caso de los virus (como el SARS-CoV-2) que tienen su material genético codificado en ARN (ácido ribonucleico), lo que vuelve más inestable su identidad genética y favorece la aparición de nuevas codificaciones, casi idénticas, pero con mínimas diferencias. En definitiva, la selección natural ha precedido la evolución de los humanos, plantas y todos los seres vivientes del planeta, y los virus no son la excepción en este sentido.

Por otra parte, nunca el mundo había estado tan interconectado como hoy en día. Nunca tantos millones de personas se desplazaron diariamente a bordo de miles de aviones, trenes, barcos y autos, desde y hacia todas partes del mundo como en la actualidad. Por ende, la "supuesta" rápida propagación y expansión territorial del virus tampoco debería sorprendernos en absoluto. Lo llamativo sería que eso no ocurriese y que, por alguna extraña razón, el virus permaneciera circunscripto a determinadas zonas o regiones. Sin embargo, contrario a lo que se piensa y se comenta, el actual coronavirus tiene una velocidad de propagación menor que el virus de la gripe común y la propia OMS lo ha admitido:

"La influenza tiene un período de incubación mediano más corto (el tiempo desde la infección hasta la aparición de los sintomas) y un intervalo en serie más corto (el tiempo entre casos sucesivos) que el virus COVID-19. El intervalo en serie para el virus COVID-19 se estima en 5-6 dias, mientras que, para el virus de la influenza, el intervalo en serie es de 3 días. Esto significa que la gripe puede propagarse más rápido que COVID-19".

Ahora bien, aun admitiendo que esta no es la única vez que ocurre una pandemia, que tampoco será la última y que la rápida propagación a nivel mundial puede deberse a factores de conectividad relacionados con el desarrollo tecnológico, podría argumentarse que este caso es especialmente grave o excepcional en comparación a los demás, por sus inusuales características y consecuencias a nivel mundial, nunca antes vistas ni conocidas por la especie humana. Pero, ¿realmente lo es? ¿Según qué criterios? ¿Quién determina esto? Y aplicando este razonamiento nuevamente al tópico que nos convoca: ¿Cuáles de las consecuencias dañosas más graves que están padeciendo actualmente personas y empresas en todo el mundo -que pueden estar potencialmente cubiertas por algún contrato de seguro- tienen realmente su causa efectiva en la pandemia trending topic y cuáles obedecen, en realidad, a otros motivos, ajenos a la intrínseca peligrosidad del virus?

Unos párrafos antes hacíamos referencia a los datos oficiales de la Organización Mundial de la Salud (OMS) con respecto a la epidemia de gripe H1N1 de los años 2009 y 2010, por ser el ejemplo más reciente. Sin embargo, más atrás en el tiempo, la Peste Negra se estima que mató aproximadamente a un tercio de la población de Europa en su tiempo ${ }^{5}$, al tiempo que la Gripe Española mató entre 60 y 100 millones de personas a comienzos del siglo XX, el equivalente a casi el 10\% de la población mundial de entonces ${ }^{6}$. También aquí en América, se estima que 14 de los 22 millones de aztecas que

\footnotetext{
4 https://www.who.int/emergencies/diseases/novel — coronavirus - 2019/question — and — answers - hub/ $\mathrm{q}$ - a - detail/q-a - similarities — and - differences - covid-19 - and - influenza.

5 https://es.m.wikipedia.org/wiki/Peste_negra.

${ }^{6}$ https://es.m.wikipedia.org/wiki/Pandemia_de_gripe_de_1918.
} 
habitaban nuestras tierras hacia el año 1520 murieron a causa de la viruela, traída por los europeos desde el Viejo Continente. El COVID-19, por su parte, lleva registradas al $1^{\circ}$ de mayo de 2020 unas 250.000 muertes oficiales (con las inconsistencias en los factores de atribución de causalidad que analizaremos enseguida), algo así como el $0,003 \%$ de la población mundial ${ }^{7}$. No parecería pues, que estuviéramos actualmente frente a un hecho extremadamente inusual o jamás ocurrido. La cobertura mediática y las medidas de confinamiento generalizado y estricto, sin embargo, no parecen ir acorde con estos números.

Por otra parte, como adelantábamos recién, se han evidenciado grandes inconsistencias en distintos países acerca de los criterios para determinar las causas de fallecimiento de las víctimas que presentan una o más afecciones o causas de comorbilidad. Esto genera diferencias sustanciales a la hora de calificar a un fallecido "por" COVID, a menudo asimilado a la noción de fallecido "con" COVID. El Dr. Walter Ricciardi, principal asesor del Ministerio de Salud de Italia ha admitido que el número de casos de fallecidos por coronavirus debe ser menor que el informado porque se han reportado como fallecidos por COVID-19 una gran cantidad de casos con hasta más de 3 causas de comorbilidad, en base a presunciones sin confirmar, criterio distinto al que ha seguido Francia, por ejemplo ${ }^{8}$. Por su parte, la propia Directora del Departamento de Salud de Illinois, Ngozi Ezike, hizo declaraciones asombrosas en conferencia de prensa (disponible en YouTube para cualquier persona) en el mismo sentido:

\footnotetext{
"me gustaría ser clara en cuanto a la definición de fallecidos por COVID. La explicación de la causa es muy simplista, significa en el momento de la muerte se hizo un diagnóstico positivo de COVID, esto significa que si estuvieras en el hospital y te quedaran pocas semanas de vida y luego resulta que también contrajiste COVID, será contabilizada como muerte por COVID, técnicamente, incluso si en realidad has muerto de otra causa pero tuvieras COVID en ese momento. Una muerte por COVID no significa que fuera la causa de muerte, sino que tenía COVID en ese momento, espero que eso esté claro".
}

Desde otra perspectiva, es interesante repasar también la información estadística que se encuentra disponible sobre las principales causas de muerte en el mundo desde 1990 en adelante ${ }^{10}$. En este contexto, podemos ver que el coronavirus no se ubica dentro de las principales 15 causas de muerte en la actualidad. El número de víctimas adjudicadas al COVID-19 está ubicado muy por debajo, incluso, del número de fallecimientos por tuberculosis, enfermedad para la cual existe vacuna disponible desde hace casi 100 años. También representan apenas un tercio de los casos que se registran año a año por suicidios y menos de la mitad de los casos de muerte por ahogamiento, por poner un par de ejemplos. Sin embargo, todos hemos visto imágenes apocalípticas, alusiones a hospitales saturados, fosas comunes que nunca existieron y demás relatos siniestros que desdibujan la realidad fría de los números y acrecientan el pánico generalizado.

\footnotetext{
7 https://worldometers.info/coronavirus/.

$8 \mathrm{https}$ //es.euronews.com/2020/02/27/un-experto-de-la-oms-dice-que-los-casos-decoronavirus - en-italia-son-muchos-menos.

9 https://www.youtube.com/watch?v=SbMaaUk58Yo\&feature=youtu.be.

${ }_{10} \mathrm{https}$ //ourworldindata.org/causes-of-death.
} 
Todo esto dificulta aún más una comprensión cabal del problema en términos epidemiológicos y convierte el terreno del debate constructivo en caldo de cultivo para la utilización de la información y sus medios para objetivos oportunistas, políticos y de control social. Se ha agigantado de una manera tan impresionante el temor a este virus, que ha quedado relegada a un plano demasiado lejano la discusión científica seria y la dimensión real del problema. No en vano se dice que el árbol no deja ver el bosque. Y si lo miramos con lupa (y tapabocas), menos aún.

Así, encontramos modelos predictivos que auguran escenarios catastróficos como el elaborado por el Imperial College de Londres (Dr. Ferguson) y citado por la prestigiosa revista Nature ${ }^{11}$ o la New England Journal of Medicine, Dr. Fauci ${ }^{12}$, con influencia directa en la política sanitaria de países relevantes como Inglaterra y EEUU, al mismo tiempo que surgen voces de importantes científicos disonantes con este panorama (Wodarg ${ }^{13}$, Ioannidis ${ }^{14}$, Wittkowsk ${ }^{15}$, Bhattacharya ${ }^{16}$, entre otros), que aseguran que el coronavirus está lejos de ser una amenaza global como está planteada actualmente y que las actuales medidas adoptadas por muchos países son, por lejos, mucho más contraproducentes que el propio virus, tanto económica como sanitariamente. Como consecuencia, es sumamente difícil encontrar consenso en cuanto a los datos sobre el COVID-19 a partir de los cuales se elaboran los índices de propagación o de letalidad, que a su vez son utilizados para realizar modelos de predicción estadística, los que a menudo están contaminados por cuestiones de política y geopolítica que afectan indudablemente el rigor científico que se espera de una información tan relevante y que luego circula por el mundo a través de sus múltiples formas.

\section{LA INCERTIDUMBRE Y LA IMPREVISIÓN}

Más allá de todas estas dificultades que veníamos repasando en relación a la enorme dificultad práctica de contar con datos fidedignos, no podemos olvidar que el contrato de seguro es, por definición, aleatorio y, en este sentido, está sometido intrínsecamente a la incertidumbre a lo largo de su vigencia. Ella es parte constitutiva de su naturaleza. Por lo tanto, para que alguna circunstancia externa tenga la posibilidad de alterar los términos de contratación de un seguro, justificando el incumplimiento de una de las partes del contrato basado en la alteración de las condiciones iniciales de la contratación, sin dudas debe tratarse de un evento con características extraordinariamente imprevisibles y debidamente acreditables y, sobre todo, dicha circunstancia

\footnotetext{
${ }^{11} \mathrm{https}: / /$ www.nature.com/articles/d41586-020-01003-6.

12 nejm.org/doi/full/10.1056/NEJMe2002387.

${ }^{13} \mathrm{https}$ ://extramurosrevista.org/que-tan-letal-es-el-coronavirus-estamos-muy-lejos-de-que-esoeste-claro-hay-espacio-para-interpretar-los-datos-de-distintos-modos-2/ $</ \mathrm{a}><$ !-EndFragment-!EndFragment-.

${ }^{14} \mathrm{https}: / /$ www.thetimes.co.uk/article/the-science-is-becoming-clear-lockdown-are-no-longer-theright-medicine-k5c652wk8</a $><$ !-EndFragment-!-EndFragment-.

${ }_{15} \mathrm{https}: / /$ youtu.be/mIKkfgdAwK8.

${ }^{16} \mathrm{https} / / /$ extramurosrevista.org/es-el-coronavirus-tan-letal-como-se-dice-las-estimaciones-actualessobre-la-letalidad-del-virus-podrian-ser-exageradas-por-varios-ordenes-de-magnitud/ $</ a><$ !EndFragment-!-EndFragment- .
} 
debe ser ajena al riesgo propio que le da sentido y razón de ser al contrato. Y no vemos que esto se cumpla en este caso.

La legislación argentina, por ejemplo, es elocuente en este sentido, ya que, si bien deja abierta la puerta a la Teoría de la Imprevisión como instituto en el propio Código Civil, claramente excluye su aplicación, en el caso de los contratos aleatorios, cuando el hecho invocado como generador de esta situación está ligado al riesgo del propio contrato. Veamos el artículo 1198 del citado cuerpo legal:

Art. 1.198. Los contratos deben celebrarse, interpretarse y ejecutarse de buena fe y de acuerdo con lo que verosímilmente las partes entendieron o pudieron entender, obrando con cuidado y previsión.

En los contratos bilaterales conmutativos y en los unilaterales onerosos y conmutativos de ejecución diferida o continuada, si la prestación a cargo de una de las partes se tornara excesivamente onerosa, por acontecimientos extraordinarios e imprevisibles, la parte perjudicada podrá demandar la resolución del contrato. El mismo principio se aplicará a los contratos aleatorios cuando la excesiva onerosidad se produzca por causas extrañas al riesgo propio del contrato.

En los contratos de ejecución continuada la resolución no alcanzará a los efectos ya cumplidos.

No procederá la resolución, si el perjudicado hubiese obrado con culpa o estuviese en mora.

La otra parte podrá impedir la resolución ofreciendo mejorar equitativamente los efectos del contrato.

La legislación uruguaya, por su parte, no es tan explícita porque ni admite el instituto, ni excluye del mismo a los contratos aleatorios a texto expreso. Como consecuencia, hasta ahora la jurisprudencia uruguaya ha rechazado sistemáticamente la Teoría de la Imprevisión como argumento para corregir supuestos desequilibrios supervinientes en contratos de ejecución continuada o de largo plazo, a pesar del invalorable esfuerzo intelectual de diversos doctrinos, algunos de gran trayectoria y renombre en la materia (Juan Blengio, Gabriel Fernández, Carlos Groisman, entre otros). De todas formas, como podemos ver, el Código de Comercio en su Art. 220, numeral 1, nos aclara que no se aplicará la regla de la Fuerza Mayor o Caso Fortuito en caso que una de las partes hubiera tomado para sí el riesgo de que algo así ocurra:

Art. 220

No se deben daños y perjuicios, cuando el deudor no ha podido dar o hacer la cosa a que estaba obligado, o ha hecho lo que le estaba prohibido, cediendo a fuerza mayor, o por caso fortuito.

No se entienden comprendidos en la regla antecedente, los casos siguientes:

1. Si alguna de las partes ha tomado sobre sí especialmente los casos fortuitos, o la fuerza mayor. 


\section{Si el caso fortuito ha sido precedido de alguna culpa suya sin la cual no habría tenido lugar la pérdida o inejecución.}

3. Si el deudor había caído en mora antes de realizarse el caso fortuito, no comprendiéndose en esta excepción el caso en que la cosa habría perecido del mismo modo, en manos del acreedor.

En este sentido, si bien es cuestionable que esta pandemia sea verdaderamente un evento que revista las características de imprevisibilidad e irresistibilidad necesarias para ser considerado un Caso Fortuito, aunque así lo fuera, es intrínseco a cualquier contrato de seguros que cubra este tipo de eventos la posibilidad que ello ocurra y, por ende, si el riesgo de pandemia está incluido en los contratos vigentes, entiendo que no puede hablarse de un Caso Fortuito no contemplado. Por lo tanto, debe cubrirse cualquier perjuicio ocasionado con origen en dicho evento. En otras palabras, encuentro injusto que aquellos contratos que cubrían el riesgo de pandemia antes de verificarse la actual situación sanitaria sean "reinterpretados" a la luz de la Teoría de la Imprevisión con la consecuente exclusión de cobertura en base a la aparición de un elemento externo, extraño, imprevisible e irresistible como la mencionada epidemia COVID-19. Es justamente lo que se pretende cubrir al contratarlo. Del otro lado de la misma moneda está la injusticia e inseguridad jurídica de pretender que aquellos contratos que no incluían dicha cobertura sean reinterpretados para que los efectos de la pandemia queden incluidos dentro de la cobertura contratada.

En efecto, se trata de un hecho que pertenece al álea constitutivo de la propia causa del seguro, esa incertidumbre que le da sentido y razón de ser al contrato. Si pensamos el riesgo en términos de frecuencia e intensidad, es absolutamente previsible que cierto universo de riesgos pueda presentar una frecuencia de siniestralidad extremadamente baja. Y no por ello dejan de ser riesgos asegurables. El mismo razonamiento aplica en términos de intensidad de los efectos del evento riesgoso. No alcanza, a mi entender, con que un evento sea extremadamente poco frecuente ni extremadamente intenso para que sea capaz de alterar el contenido obligacional del contrato de seguro. La imprevisibilidad viene de la mano de lo esperable que puede ser un evento, si pudo ser representado hipotéticamente o no de alguna manera, $\mathrm{y}$, en este sentido, no encuentro ningún elemento anormal en el caso de esta emergencia sanitaria que se ha instalado a nivel mundial.

Finalmente, me permito hacer breves comentarios acerca de la también interesante postura que sostiene que estamos frente a una situación que supone un agravamiento de riesgo para las aseguradoras y que, en base a ello, éstas podrían negarse a cubrir los efectos económicos adversos derivados de la actual coyuntura sanitaria y social ya que se trataría de una situación no contemplada inicialmente, que de haber existido en su momento, habría modificado las condiciones de la contratación o habría impedido el perfeccionamiento del contrato de seguros. Pues bien, la línea argumental es esencialmente la misma: ¿cómo explicamos que un asegurador no podía haber contemplado jamás la posibilidad del acontecimiento de una pandemia como la presente en un contrato que incluye cobertura contra pandemias, epidemias o interrupción del negocio, siendo que se trata de un fenómeno que ocurre con periodicidad en el mundo? ¿Cuál sería sino el contenido de un contrato que tenga por objeto cubrir estos 
riesgos? Por otra parte, si bien puede hablarse de un aumento de riesgo para determinadas coberturas como consecuencia de esta situación actual, también es claro que en muchas otras líneas de negocio esta realidad supone una disminución dramática de la exposición al riesgo. Pensemos tan solo en las coberturas de daños materiales y personales por accidentes de tránsito, accidentes laborales y accidentes en general. Esta detención generalizada de las actividades a nivel mundial necesariamente implicó una disminución de la siniestralidad en muchas áreas de riesgo y ello no es menor, ya que constituye un balance, un equilibrio natural en la percepción consolidada del riesgo para una empresa aseguradora.

\section{4. ¿PANDEMIA O LOCKDOWN?}

Mención aparte merece el abordaje de la cuestión desde la óptica de la cobertura de los riesgos asociados a la obediencia civil a las decisiones gubernamentales relacionadas con el cierre intempestivo de una enorme cantidad de locales comerciales. Obviamente, estas decisiones - acertadas o no- tienen su origen en el riesgo a la expansión del virus y están relacionadas directamente con un estándar de prudencia que debe regir la función gubernamental de un país, más aún al estar asociado a un virus que no se conocía hasta ahora, y teniendo en cuenta la poca información -y de mala calidad- que ha influido en los asesores en materia sanitaria de las esferas políticas más importantes a nivel mundial. Para la población, frente a estas decisiones no queda otra alternativa que obedecer, so pena de cometer ilícitos que pueden acarrear multas y hasta la prisión en algunos casos. Como consecuencia, los propietarios de negocios no pueden hacer otra cosa más que resignarse a ver cómo pasa el tiempo mientras los clientes y las ganancias no aparecen y los vencimientos de las obligaciones preasumidas no dejan de caer.

Ahora bien, estos daños económicos ¿tienen su origen en la pandemia -en tanto fenómeno sanitario- o en el lockdown impuesto por las autoridades por el miedo a aquélla? Desde la perspectiva de la causalidad inmediata efectiva no cabe duda que, el hecho generador del perjuicio es la orden de la autoridad competente que obliga a los negocios a cerrar. De este modo, en aquellos países donde se han adoptado medidas más estrictas de confinamiento, incluyendo el cierre de negocios, las pólizas que cubran el riesgo de interrupción de negocios y no excluyan el cierre de emergencia (lockdown) deben hacer frente a las pérdidas que efectivamente sufran las empresas a causa de esta situación. Y deben hacerlo aun cuando no incluyan dentro de las coberturas contratadas el riesgo de pandemia, en tanto, no se trata necesariamente de pérdidas ocasionadas por la enfermedad en sí, sino por la decisión de las autoridades de obligar a la población a someterse a una cuarentena generalizada. Y ese es, justamente, el riesgo que el asegurado no quiere asumir -y por ende decide transferirlo al asegurador- al contratar un seguro que cubra en casos de interrupción de negocios. Bajo el mismo argumento, deberían estar obligadas a cumplir con la debida indemnización, aquellas pólizas que cubren pérdidas de ganancias de forma genérica, usualmente bajo coberturas tipo "paraguas" o llamadas "todo riesgo", en las cuales no se haya previsto específicamente como exclusión de cobertura la causal de lockdown. Entiendo que la 
poca precisión en estos casos juega en contra de los intereses del asegurador, en tanto es la parte predisponente de los textos de póliza.

Por último, otro aspecto interesante a plantear sería la posibilidad, por parte de las aseguradoras, de repetir contra el Estado a título de responsabilidad por acto legislativo o ejecutivo, en cada caso, por haber adoptado decisiones extremadamente dramáticas y desproporcionadas, que restringen algunos de los derechos más fundamentales de las personas -como el derecho al trabajo y a la libertad ambulatoria en general- con gravísima afectación en la economía de los países, sin contar con la evidencia fáctica y científica suficiente que lo amerite y sin haberse tomado el trabajo de acceder a información imprescindible para una toma de decisiones de estas características. En definitiva, es una decisión política que, como todas, tiene sus consecuencias y el Estado, como bien sabemos, es un sujeto de derecho más, y como tal es pasible de imputación jurídica, desde luego.

\section{REFERENCIAS BIBLIOGRÁFICAS}

1) https://www.who.int/csr/don/2009_11_27a/en/.

2) Heath, Kelly; Peck, Heidi A.; Laurie, Karen L. (5 de agosto de 2011). «The AgeSpecific Cumulative Incidence of Infection with Pandemic Influenza H1N1 2009 Was Similar in Various Countries Prior to Vaccination».PLOS One.

3) «First Global Estimates of 2009 H1N1 Pandemic Mortality Released by CDC-Led Collaboration | CDC». cdc.gov (en inglés). 25 de junio de 2012. Consultado el 31 de enero de 2020.

4) https://www.who.int/emergencies/diseases/novel-coronavirus-2019/question-andanswers-hub/q-a-detail/q-a-similaritie-and-differences-COVID-19-and-influenza.

5) https://es.m.wikipedia.org/wiki/Peste_negra.

6) https://es.m.wikipedia.org/wiki/Pandemia_de_gripe_de_1918.

7) https://worldometers.info/coronavirus/.

8) https://es.euronews.com/2020/02/27/un-experto-de-la-oms-dice-quelos - casos - de - coronavirus - en - italia - son-muchos - menos.

9) https://www.youtube.com/watch?v=SbMaaUk58Yo\&feature=youtu.be.

10) https://ourworldindata.org/causes — of - death.

11) https://www.nature.com/articles/d41586-020-01003-6.

12) nejm.org/doi/full/10.1056/NEJMe2002387.

13) https://extramurosrevista.org/que-tan-letal-es-el-coronavirus-estamos-muy-lejosde-que-eso-este-claro-hay-espacio-para-interpretar-los-datos-de-distintos-modos- $2 /</ \mathrm{a}><$ !-EndFragment- ! -EndFragment-.

14) https://www.thetimes.co.uk/article/the-science-is-becoming-clear-lockdowns-areno-longer-the-right-medicine-k5c652wk8</a $><$ !-EndFragment- ! -EndFragment-.

15) https://youtu.be/mIKkfgdAwK8.

16) https://extramurosrevista.org/es-el-coronavirus-tan-letal-como-se-dice-as-estimaciones-actuales-sobre-la-letalidad-del-virus-podrian-ser-exageradas-porvarios-ordenes-de-magnitud $/</ a><$ !-EndFragment-!EndFragment-. 
